\title{
The Body: \\ From Virtual Avatar to Plastic Surgery
}

\author{
Hassan Choubassi \\ The International University of Beirut \\ Michel Abi Chahla street, Mousytbeh \\ Beirut-Lebanon \\ hassan.choubassi@b-iu.edu.lb
}

\author{
Sahar Sharara \\ The International University of Beirut \\ Michel Abi Chahla street, Mousytbeh \\ Beirut-Lebanon \\ sahar.sharara@b-iu.edu.lb
}

\begin{abstract}
From Photoshop to plastic surgery there lies a transaction of reality from the virtual to the actual; from digital image manipulation to physical body sculpting, a distance for explosion. What imploded in the virtual in the form of fantasy has now returned in the form of violent corporal mutation. This is a commodification of the human body, the plastic body as such, is the perfect body that everybody achieved with Photoshop and other image manipulation software in virtual reality and that has reached the physiological body with the augmentation tools of medical technologies,
\end{abstract}

The human body is now reproduced following a set of standards, measurements and beauty references to fit under one of the pre-set categories dictated by the mass culture. The result of this computed type of production is an unprecedented uniformity. Everybody looks like everybody now, in actual reality there is a set of categories that each group of people fits in exactingly. This capitalist culture industry of mass production is still triumphant today but with new, more powerful, technologies of augmentation that are employed to facilitate this corporal metamorphosis. This implies that something went wrong in the use of new technologies. Today the production of sameness is more then ever locking us towards a catastrophic image of massproduced disfigured bodies where violence persists as the main patent of post virtual-reality image.

Photoshop. Plastic surgery. Virtual reality. Augmented reality. Image manipulation. Human commodification.

\section{INTRODUCTION}

The advent of image manipulation Softwares into the market in the 90s, namely Photoshop, and its wide accessibility and usability by the public marked an unprecedented hyper-real image in quality and, because of it easiness, a large quantity of images. Now anybody can take any image and do whatever with it, Photoshop was widely used by the public to aesthetically enhance the image of the human figure. In addition to that, some other Softwares and Applications had the option to automatically modify and enhance the images without even notifying the user, and thus image improvement, like red-eye fixer and bright-skin garnish were becoming normal. This normalized image of the "perfect" human figure led eventually to demand that that image becomes also applicable on the physical body itself, that ultimately led to plastic surgery in actual reality or augmented reality.

\section{THE PERFECT BODY}

This heed for the perfect body that originates from the pop image was depicted early in the In 90's by the French artist Orlan as she started a series of chirurgical performances entitled "The Reincarnation of Saint-Orlan" (Orlan, n.d.) where she tried to transform her body into the perfect female body through a set of plastic surgeries that will enact the paintings of the icons of beauty created by major male artists. In that work Orlan is criticizing the standardization of female beauty and 
how it is manufactured to convey the main stream image of females through the eyes of male artists, or in a more contemporary manner, by media gurus, fashion industry and pop stars criteria's.

When living in the virtual reality period, people gave away their physical existence with it their physical body. They learned to be less dependent on their bodily existence and thus they worked on hiding this corporal mass with different interfaces created and generated by computers. The perfect body under virtual reality is a "silent body" it became the Deleuzian body; A body that does not have any physical needs, a "body without organs" or an image of a body that is a manifestation of a deeper reality constructed from fully functioning virtual parts. Every actual body has a virtual dimension, a vast collection of paradigms that constructs its personality, its links, its distresses and its fluxes. This collection of paradigms is what Deleuze calls the "Body without Organs". But eventually this body without organs becomes the virtual dimension of the totality of actual reality itself or the terrestrial glob, in their "A thousand plateaus: capitalism and schizophrenia" Deleuze and Guttari wrote:

\begin{abstract}
"The Earth -the Deterritorialized, the Glacial, the giant Molecule- is a body without organs. This body without organs is permeated by unformed, unstable matters, by flows in all directions, by free intensities or nomadic singularities, by mad or transitory particles (...) There simultaneously occurs upon the earth a very important, inevitable phenomenon, that is beneficial in many respects and unfortunate in many others: stratification. Strata are Layers, Belts. They consist of giving form to matters, of imprisoning intensities or locking singularities into systems of resonance and redundancy, of producing upon the body of the earth molecules large and small and organizing them into molar aggregates". (Deleuze and Guattari, 1987, p. 40)
\end{abstract}

In cyber space, people professed the creation of avatars, they mastered regenerating their bodily image with a perfect hyper corporality. The fantasized human in virtual reality is a utopian existence where people are able to fulfil all their caprices and can live life to the extreme; they can satisfy their most intense whims. But eventually this human physiological body is here and now, present and heavy. The physical needs of that body are cumbersome, it ages and gets tired and requires a lot of maintenance. This body "full of organs" is driven by instinctive needs of love and hate, of life and death, of physical needs like eating, sleeping and having sex and thus driven by desires that can never be fulfilled in the virtual. In "Globalization and the Manufacture of Transient Events" Bilal Khbeiz wrote:

"No longer is it sufficient to hide the body and the signs of its basic needs. The effects of time are also considered ravages that must be fixed and hidden. Tired eyes are reviled. Sufficient sleep or its equivalent is stipulated to maintain the appearance of bloom and vigor. A similar attention is required for sustaining the bright whiteness of teeth so they seem always unused" (Khbeiz, 2003).

This transition of the body from the physical to the virtual avatar and back again to its physicality (equipped with electronic devices, a cyborg) required a transformation in the means of technologies of communication first and foremost, then it required a transformation in the notion of space and time, public space versus private, and present time versus real time. The preparation of the body for disappearance, for a silent physicality that enables it to enter the realm of the virtual as an image, required a lot of efforts and skills. In that world of images what remains from the tangible body is only what is necessary for its basic survival, and the organs that allowed it to connect to the machine. The body must be maintained to create a spectacle for the screen, powdered and cleansed, ready to be under the spot, in the shopping windows of the virtual. A body as such, is a body that suggests energy while it is flabby, strength while it is weak, new and unused while it ravaged by time; a re-delivered baby-body that is hundred years old. This energetic and vigorous body marginalizes few of its irreplaceable senses; it becomes a taste-less and smell-less body and thus outside the realm of conventional space of touch and proximity, into the hyper non-space of the three dimensional illusion of the screen that distances the interlocutors physical bodies apart. In that space the body is guided by different parameters of vectors and digital formulas not anymore by its tangible senses. As for vigor, it is replaced by the discourse of potency and substituted by a language able to feign that existence is unobstructed by the invalidity of physical bodies. And thus, throughout the heydays of virtual reality, those actual living bodies are avoided keeping of them, as Khbeiz suggests: "nothing but their surplus images, well chosen and scanned, images of bodies overflowing with health and channelled with energy (...) As such, the body ceases to be a land of enigmas and miscarriages and appears, instead, endlessly malleable to the whims of the imagination. This malleability precipitates the migration of the body from the province of magic to the domain of functionality, which is in itself a first and irreversible step towards mourning" (Khbeiz, 2003), and towards the death that Ulysses warned his sailors from; a death of the enigmatic physiological body and the birth of an ultimate image-body that suggests and posses an ultimate image of holistic truth "what was, what is and what will be". 


\section{PLASTIC SURGERY AS A RESTRAINT}

This holistic truth that has emigrated to a virtual reality of a utopian or, more precisely, tele-topian existence is still "lacking in one element, its presence in time and space, its unique existence at the place where it happens to be" (Benjamin and Arendt, 1999) its "Aura" as an actual existence that can never be utopian, on the ground, in the desert of the real. The human body is back again, heavy and cumbrous as it ever was, although categorized into definite provinces and meticulously sculpted into the norms and criteria of ideals. The body is to be maintained by arduous physical training, diet, refinement and a set of varieties of cosmetics to embody ideals. But throughout that process the filter of the culture industry excludes a large range of bodies that are not able to pass that fascist strainer; old and aging bodies will not pass, sick and weak bodies will not pass, the handicapped and the hindered bodies are directly categorized as invalid and incorrect bodies that will eventually fade on the margins of this society. What remains on the façade of the spectacle, on mainstream media is a constant parade of models and paradigmatic perfect bodies that are the most efficacious apparatus for the spectacle. The last resort to contain that body becomes the scalpel; violent acts of surgery to put it back into order. Here comes "plastic surgery" as an act of restraint, a freakish act of control, of persecution that will eventually leave the physiological body with deep scars. Plastic surgery as it is professed toady is becoming an act of mutilation that is disfiguring the human body to confine it into the norms of a fantasized image, an image that was long lived as an avatar, becomes today the norm and the reference for the perfect body.

The practice of plastic surgery has increased to an unprecedented level in the past few years, (For example; according to a report on '66 minutes' from M6 Channel, entitled: "get ready for it, Beirut, Supermarket of Plastic Surgery and lifting", one in every three women In Lebanon has undergone a plastic surgery. With more than one and half interventions per year, Lebanon is the number one in the world in plastic surgery, Seven times the rates in France) and this is not due to medical reasons of reconstruction but rather only for aesthetic reasons. The idea of a perfect self-image that has dominated the popular culture for several years in the virtual has led to this extreme measure of physiological modification. The heed to resemble pop stars or fashion models in a magazine, or just to fit into the beauty standards set by mainstream media becomes the dominant concern of people, and soon it becomes a norm that one should undergo a surgery if she/he does not fit into a category or fulfil a standard. Plastic surgery is not a luxury anymore or an added asset, it is becoming more of a must, if a person do not convey to the norm of the main-stream image she/he will be marginalized in a society that is more and more accustomed to sameness in addition to this urgency of self defacement, plastic surgery becomes accessible and affordable for most of the people. Costs of a nose job now ranges between $\$ 1,000$ to $\$ 3,000$ US dollars, in a flyer that was recently distributed in the streets of Beirut there is a list of surgeries one can conduct with a pricelist that looks so much like a menu in a restaurant, that's how easy and accessible those surgeries are becoming in Lebanon. Some banks are even giving loans for people eager to undergo a certain surgery but cannot afford to do it, The First National Bank in Beirut offers a loan that can go up to $\$ 5,000$, with this money "you have the freedom to make the changes you feel are necessary in your life" As they mention on their website ("First National Bank," n.d.). An article in the BBC news on April 2007 shows how flagrant the situation is and how much the heed for plastic surgery has increased in Lebanon (BBC News, 2007). In Lebanon like otherwise in the world, plastic surgery became part of the mainstream beauty industry, with variations of Rhinoplasty, Botox injections, fat injections in cheeks and lips, nose job or revision, brow lifting, chin reduction, ear back pinning operation, neck liposuction, breast augmentation or revision, liposuction on waist and thighs, and buttocks augmentation. The standard references for plastic surgery modifications are mostly coming from the mainstream images of pop stars singers, pinup artists, movie actors, politicians or even, clandestinely, porn stars; apparently everyone wants to resemble the artificial plastic beauty that was long experimented in virtual reality. Plastic surgery in that case can be seen as a process to virtualize the human body, among other techniques and situations of virtualization, like heavy makeup, tattooing, spectacles and red districts display windows; plastic surgery is the most radical process that has irreversible effects, it is in a way a trial to transform the actual into an image. In virtual reality the image was itself the actual, a reality which is itself image, but today plastic surgery is one of the processes of augmenting the actual from virtual references.

\section{PRODUCTION OF SAMENESS}

In "The Culture Industry: Enlightenment as Mass Deception" (Horkheimer and Adorno, 2007) Max Horkheimer and Theodor Adorno argue that cultural production under capitalist modernity is bound to fall under specific categories and following pre-set standards in a way to fit into the filter of the market economy. This filtering of cultural production leads to the commodification of the work of art and thus reducing its artistic and 
creative value into mere economical worth and transforming it into a vulnerable pry for competition with mass-produced pop commodities, and as Adorno and Horkheimer said:

\begin{abstract}
"A technological rationale is the rationale of domination itself. It is the coercive nature of society alienated from itself. Automobiles, bombs, and movies keep the whole thing together until their leveling element shows its strength in the very wrong which it furthered. It has made the technology of the culture industry no more than the achievement of standardization and mass production, sacrificing whatever involved a distinction between the logic of the work and that of the social system." (Horkheimer and Adorno, 2007, p. 95)
\end{abstract}

When Adorno and Horkheimer wrote their critic of enlightenment it was still in its original stage, enlightenment was supposed to be an advance of thought and its objectives were supposed to be aimed at human liberation from the forces of nature to install them as masters of their existence and thus masters of the world, with an abundance of freedom and an abundance of happiness, yet what it delivered is total calamity, and distress. Technological progress of modern science in medicine, in arts and in all sorts of industrial production assured happiness and freedom to humans through reason and promised to unfetter people from the constraints of ignorance and cruelty, from violence and hardship; but it delivered the opposite, Instead it helped create a world where people will commit atrocities, and will willingly practice methodical killing, and enthusiastically develop weapons of mass destruction. The failures of modern rationality is regenerating with a new face today in what is supposed to be a post -modern setting, and yet again another time, the technological rationality of the capitalist mode of production failed to fulfil the initial promises of happiness and freedom that it always bragged about. There still is a lack of freedom in today's politics, economy and legal structures that indicate an associated failure in the culture enlightenment. This only implies that something fundamental went wrong in the use of new technologies, or maybe it is better to say abuse of those technologies. Today the production of sameness is more then ever locking the world towards another catastrophe of image production where violence persist as the main patent of that post virtual-reality image. The same patterns of domination that were dominant in the 60's are still valid and effective today; the domination of nature by human beings, the domination of nature within human beings, and most importantly, the domination of some human beings by others. Such patterns of domination persist due to an essential factor of the crowed psychology, the irrational fear factor (Bon, 2013).
In a society that lives an illusion of freedom and where free choice is actually choosing between sameness, and when culture becomes a chases of fame and fortune no matter what the cost; the "other" bares the pains and dreads for that pursuit and is shunted away, exploited, or even violently demolished. The means of destruction are yet technologically advanced and more sophisticated then ever before and the exploitation may seem less direct than outright slavery, but domination of humans over other humans remains and is now greater and has global magnitudes. The sole motivation of that practice is again the everexpanding capitalist economy. Today, fundamental change seems impossible and people are becoming more dedicated to the normalized facts and life conditions of mediocrity.

\section{CONCLUSION}

What is happening today is a commodification of the human corporality on a large scale, the plastic body is in a that sense the perfect body that everybody sought when assembling an avatar in virtual reality and now reached physiologically with a reality augmented by medical new technologies,

The augmented hominoid body becomes a norm, and is mass reproduced even before it becomes a cybernetic creature; it is produced under rigorous criteria of aesthetics, a set of standards, measurements and capacities that reconstructs the body to fit it under one of the pre-set categories dictated by the mass culture. The result of this computed type of production is an unprecedented uniformity. Everybody looks like everybody now, in actual reality there is a set of categories that each group of people fits in exactingly; a group that look like a certain pop star for example or another that has the same feature of pinup artist or just following the criteria of beauty set by fashion magazines and TV commercials. This capitalist culture industry is still triumphant today with the new, more powerful, technologies of augmentation that are ever in use since the day one of their invention, and sometimes invented only for the market use of augmentation.

\section{REFERENCES}

BBC News, 2007. Nip'n'tuck loans offer in Lebanon [WWW Document]. URL http://news.bbc. co.uk/2/hi/middle_east/6577497.stm

Benjamin, W., Arendt, H., 1999. Illuminations. Pimlico, London.

Bon, G.L., 2013. The Crowd: A Study of the Popular Mind. CreateSpace Independent Publishing Platform. 
Deleuze, G., Guattari, F., 1987. A thousand plateaus: capitalism and schizophrenia. University of Minnesota Press, Minneapolis.

First National Bank [WWW Document], n.d. FNB's Plast. Surg. Loan Beauty Is No Longer Lux. URL http://www.fnb.com.lb/index.php? option=com_content\&view=article\&id=25\&l temid $=37$

Horkheimer, M., Adorno, T.W., 2007. Dialectic of Enlightenment, 1st ed. Stanford University Press.

Khbeiz, B., 2003. Globalization and the Manufacture of Transient Events. The Lebanese Association for Plastic Arts, Ashkal Alwan, Beirut.

Orlan, n.d. The Reincarnation of Saint-Orlan. 